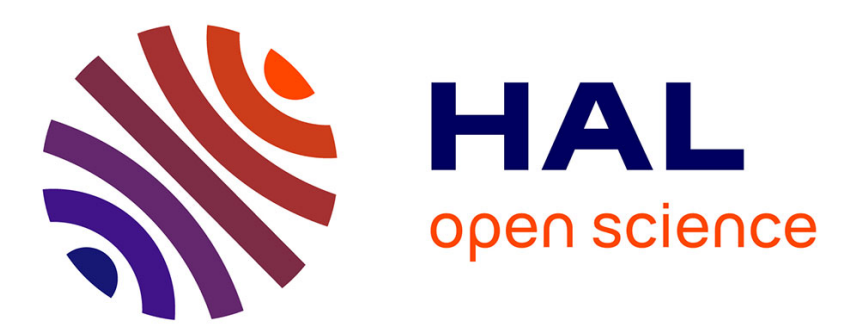

\title{
A computational model for amplitude modulation extraction and analysis of simultaneous amplitude modulated signals
}

\author{
C. Lorenzi, Frédéric Berthommier
}

\section{- To cite this version:}

C. Lorenzi, Frédéric Berthommier. A computational model for amplitude modulation extraction and analysis of simultaneous amplitude modulated signals. Journal de Physique IV Proceedings, 1994, 04 (C5), pp.C5-379-C5-382. 10.1051/jp4:1994578 . jpa-00253073

\section{HAL Id: jpa-00253073 https://hal.science/jpa-00253073}

Submitted on 1 Jan 1994

HAL is a multi-disciplinary open access archive for the deposit and dissemination of scientific research documents, whether they are published or not. The documents may come from teaching and research institutions in France or abroad, or from public or private research centers.
L'archive ouverte pluridisciplinaire HAL, est destinée au dépôt et à la diffusion de documents scientifiques de niveau recherche, publiés ou non, émanant des établissements d'enseignement et de recherche français ou étrangers, des laboratoires publics ou privés. 


\title{
A computational model for amplitude modulation extraction and analysis of simultaneous amplitude modulated signals
}

\author{
C. LORENZI and F. BERTHOMMIER*
}

LEACM, Université de Lyon 2 Lumière, 69676 Bron cedex, France

* ICP, INPG, 46 avenue Félix Viallet, 38031 Grenoble cedex, France

\begin{abstract}
The existence of amplitude-modulation (AM) frequency-specific channels has previously been suggested on the basis of psychoacoustical experiments using an adaptation or masking paradigm. Electrophysiological studies have also shown that cochlear nucleus chop-s neurons are tuned to specific AM frequencies. We have developed a simple but physiologically plausible model of chop-S neuron properties based on a digital integration of Hodgkin and Huxley equations. Although it does not include an exhaustive peripheral processing, our model produces similar results to physiological data. We recover a bandpass AM transfer function at high input levels and non-linear filtering. This model enables us to simulate physiological masking situations in the modulation domain. We examine the strength of the model synchronous response to white noises modulated at two different frequencies and added with various intensity ratios. Simulations show that the chop-S model enhances AM separation of a well-tuned AM frequency added to another, relative to the auditory-nerve fibers inputs. Masking patterns computed by varying the masker-modulation frequencies show the recruitment of the neuron by these stimuli.
\end{abstract}

\section{INTRODUCTION.}

AM plays a role in many perceptual phenomena such as complex sound sources segregation or pitch perception. Earlier psychoacoustical findings indicate that the human auditory pathways contain channels selectively tuned to particular AM frequencies. The existence of such channels has been suggested on the basis of experiments using the adaptation paradigm $(1,2)$ and the classical masking paradigm $(3,4)$. The latter investigates the detectability of a test modulation in the presence of a masker modulation, as a function of the frequency difference between test and masker modulation. Typical bandpass modulation masking patterns have been obtained using a broadband-noise carrier. The greatest amount of masking occurs when the signal and masker modulation frequencies are the same. In the same way, recent studies on neural responses to AM tones indicate a tuning of the auditory system for the detection of modulation. Sustained chopper-type neurons (chop-S) in the anteroventral cochlear nucleus (AVCN) preferentially amplify $A M$ information relative to their auditory nerve (AN) imputs, in the rauge between 50 and $500 \mathrm{~Hz}$. Amplification is achieved by stronger synchronous response to AM period in the AVCN than in AN fibers (5). Moreover, realistic physiological models of AVCN units have been recently developed $(6,7,8,9,10)$. Masking experiments with AVCN cells may be very useful in order to observe possible correlations between neural and psychoacoustical data. The purpose of this study is to investigate AM selectivity with preliminary masking experiments, in light of a computational model of AVCN chop-S units properties. 


\section{THE COMPOSITE MODEL.}

\subsection{Model description}

We describe three stages in our chop-S neuron composite model :

(1) The first stage is a model of hair cell transduction. Signal is sampled at $10 \mathrm{kHz}$, half-wave rectified and coded by an array of 50 independent Poisson point processes.

(2) The resulting 50 spikes trains are linearly / spatially summated and generate EPSPs (exponential excitatory function) of $6 \mathrm{~ms}$ duration, simulating dendritic filtering.

(3) The temporally summated EPSPs are finally converted into action potentials by Hodgkin \& Huxley (HH) equations. HH equations simulate the time course of the chop-S neuron membrane potential during stimulation. Refractory period duration is equal to $4 \mathrm{~ms}$.

Simulations are performed on a personal computer; the model was initially adjusted until it shows realistic properties.

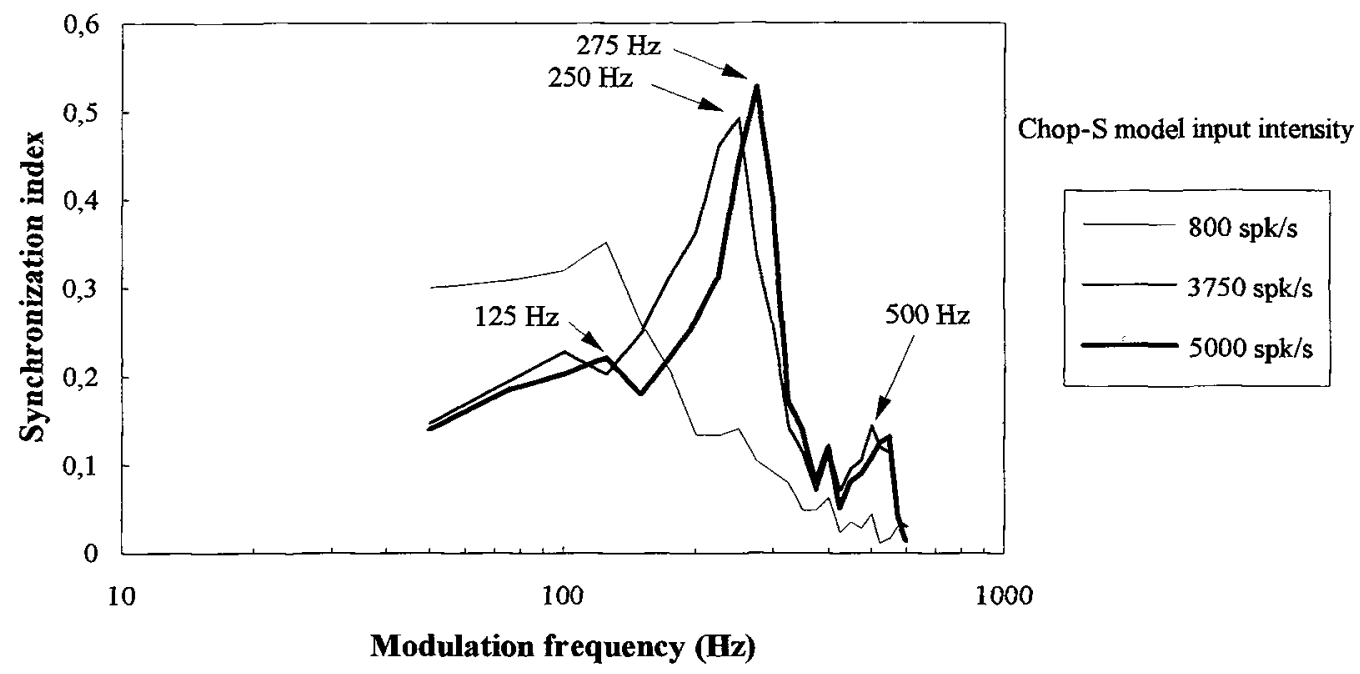

FIG. 1. Chop-S model synchronization index as a function of modulation frequency, computed for three input amplitudes. The stimulus is a $100 \mathrm{~ms}$ SAM white noise with $50 \%$ modulation depth, repeated 250 times. Arrows indicate the peak modulation frequencies (Model refractory period duration $=\mathbf{4} \mathrm{ms}$ ).

\subsection{Preliminary evaluation of the model}

To test phase-locking of the model to AM period, white noises of 100-ms duration, sinusoidally amplitude modulated (SAM) with $50 \%$ modulation depth (m), are used as inputs. Figure 1 gives the synchronization coefficient for the computer simulation as a function of modulation frequency and three input intensities. Modulation frequencies range between 50 and $600 \mathrm{~Hz}$. Chop-S model direct input intensities are quantified by the mean first stage outputs and respectively correspond to 800,3750 and 5000 spikes/s. Synchronization functions of AN fibers are roughly constant and noisy. Although the model does not include an exhaustive peripheral processing, it replicates, at least qualitatively, the main features of real AM transfer functions in the synchronization domain, namely a low-pass filtering at low input levels (800 spikes/s) and bandpass functions at high input intensities. It therefore emphasizes that AM selective enhancement performed by chop-S units is mainly due to stages 2 and 3 of the composite model. In a previous paper, we have shown that the preferential-modulation frequency (pmf) peak $(250 \mathrm{~Hz}$ at an input intensity of 3750 spikes/s) is determined by the refractory period duration of the HH system (10). Figure 1 also shows secondary synchronization peaks at about half and twice the pmf, asking further experimental confirmation. In addition, a small non linearity is observed : pmf increases slightly by about $25 \mathrm{~Hz}$ as the 
input intensity increases from 3750 to 5000 spikes/s. These data compare favourably to real data $(5,9)$, but the model also shows a little secondary modulation frequency peak at about half the pmf.

\section{MASKING EXPERIMENTS.}

It is of interest to simulate masking patterns in the modulation domain because of the non-linear properties of the model. Our method for investigating physiological masking is to examine the response of the chop$\mathrm{S}$ unit model to two SAM white noises of $100 \mathrm{~ms}$ duration $(\mathrm{m}=50 \%)$, presented simultaneously. The test stimulus is modulated at the pmf of the chop-S model $(250 \mathrm{~Hz})$. The masker is modulated at $150 \mathrm{~Hz}$ or $350 \mathrm{~Hz}$. Total input intensity is held constant at 3750 spikes/s while Test-to-Masker (T/M) ratio is systematically varied. The chop-S model fires at its saturation rate $(250 \mathrm{spikes} / \mathrm{s})$. Synchronization index values for responses to test and masker stimuli are computed for each pair of combined sounds and plotted in figure 2 as a function of T/M ratio. Phase-locking increases with stimulus amplitude. At a $0 \mathrm{~dB}$ $\mathrm{T} / \mathrm{M}$ ratio, AN fiber models display identical phase-locked responses to test and masker stimuli. The $-4 \mathrm{~dB}$ and $-9.5 \mathrm{~dB} \mathrm{~T} / \mathrm{M}$ ratios necessary to obtain identical synchronization index values in response to test and masker stimuli reflect the capacity of the chop-S unit model to enhance AM contrast between a well-tuned frequency $(250 \mathrm{~Hz})$ and another additional frequency $(150 \mathrm{~Hz}$ or $350 \mathrm{~Hz})$. Notice that separation seems greater at masker modulation frequencies above $p m f$.

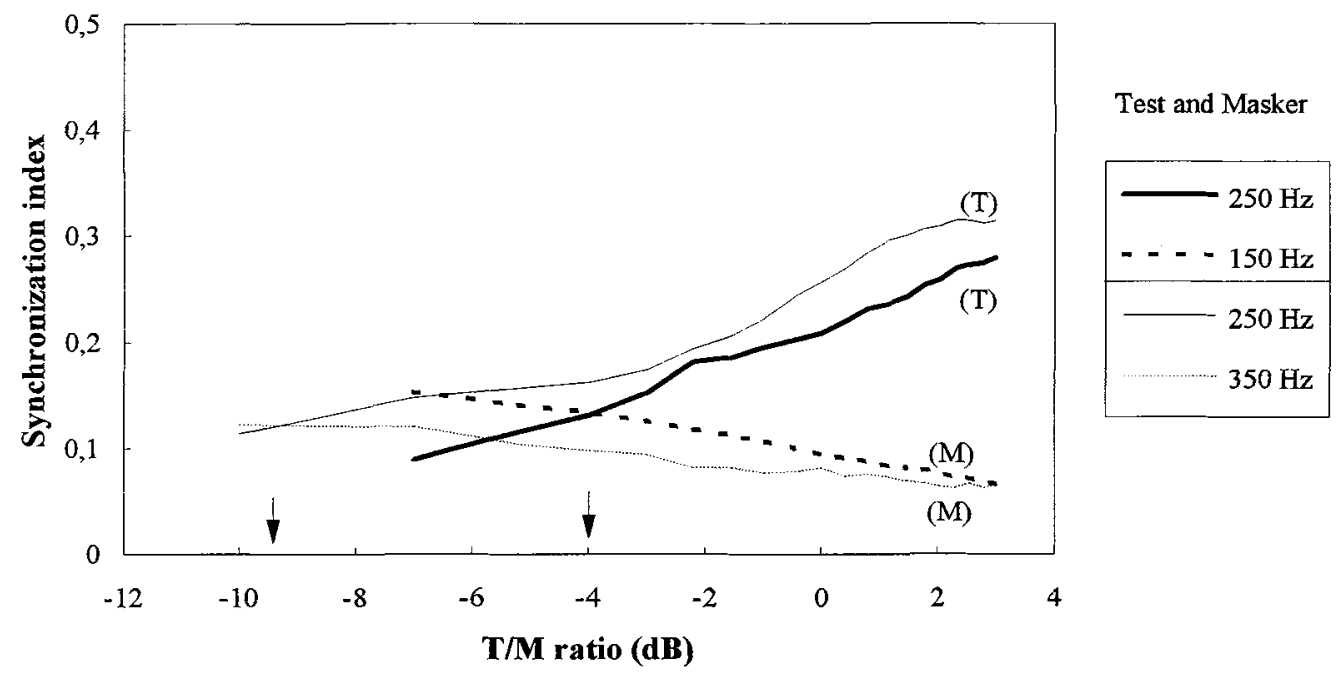

FIG. 2. A $250 \mathrm{~Hz}$ SAM test-stimulus is added to a $150 \mathrm{~Hz}$ or $350 \mathrm{~Hz}$ SAM masker-stimulus. Chop-S model synchronization index values are computed for the responses to masker and modulation stimuli, as a function of T/M ratio. [Test and Masker : SAM white noises, $m=50 \%, 100 \mathrm{~ms}$ duration]. Arrows indicate the $T / M$ ratios necessary to obtain identical phase-locking to test and masker modulation.

Masking pattern of a $250 \mathrm{~Hz}$ test modulation is finally obtained by varying systematically the masker modulation frequency (see fig. 3). Stimuli are $100 \mathrm{~ms}$ duration SAM white noises $(\mathrm{m}=50 \%)$. Total input intensity is held constant at 3750 spikes/s. Test and masker stimuli are added with different $\mathrm{T} / \mathrm{M}$ ratios. The masking effect is given in terms of synchronization ratio and calculated as $S_{m} / S_{t}$, where $S_{m}$ and $S_{t}$ are respectively synchromization index values computed for responses to masker and test stimuli. Two predictions may guide physiological and psychoacoustical experimentations. Figure 3 shows strong phaselocking on the test period when the masker intensity is low $(3 \mathrm{~dB})$. The masking ratio mainly reflects the neuron sensitivity for this frequency tuned to the $p m f$. Conversely, a weaker test intensity $(-3 \mathrm{~dB})$ produces a more complicated situation because masker competes with the test. A two peaks curve emerges, reflecting the sensitivity of the neuron to frequencies adjacent to $\mathrm{pmf}$. The model also predicts a little secondary peak of masking at two times the test modulation frequency $(500 \mathrm{~Hz})$. 


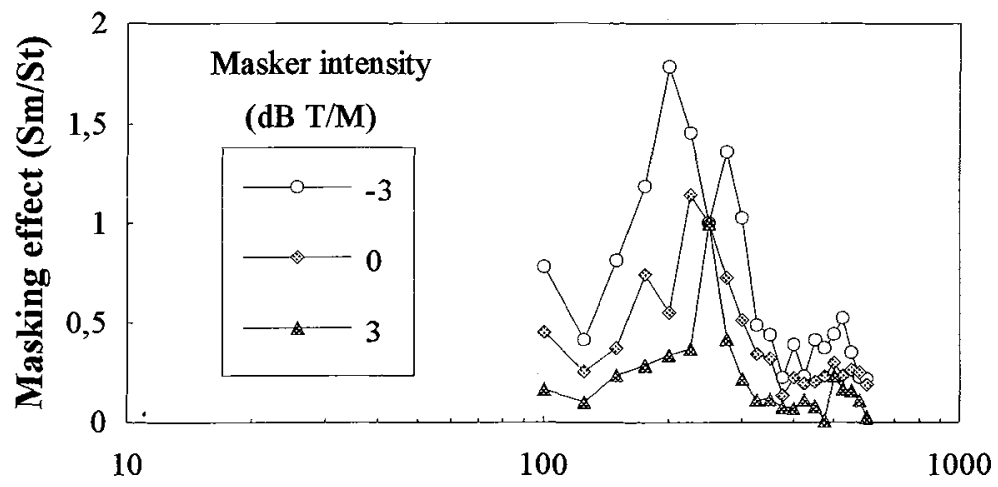

\section{Masker-modulation frequency $(\mathbf{H z})$}

FIG. 3. The masking ratio of the chop-S model in response to a $250 \mathrm{~Hz}$ SAM white noise (test) is calculated as a function of the masker-modulation frequency. Each of the three peaked curves represents the masking pattern computed with three different $T / M$ ratios.

\section{CONCLUSIONS.}

We have presented and evaluated a minimal composite model able to mimic chop-S units responses recorded in the AVCN. Simple simultaneous masking experiments with the chop-S unit model enable us to predict physiological masking patterns with secondary masking peaks related to the best modulation frequency. This result is not trivial because of the non-linear chop-S unit AM transfer function. Although it is tempting to associate the present data to psychoacoustical bandpass masking patterns $(3,4)$, they are not directly equivalent because we have to link neural and systemic levels. In this perspective, the most important problem to clarify is the determinism of complex sounds segregation in the intermediate levels of the auditory system.

\section{REFERENCES.}

(1) Kay R.H., Phys. Rev. 62 (1982) 894-975.

(2) Tansley B.W. and Suffield J.B., J. Acoust. Soc. Am. 74 (1983) 765-775.

(3) Bacon S.P., Grantham D.W. and Van Campen L.E., J. Acoust. Soc. Am. Suppl. 183 (1988) S35.

(4) Houtgast T., J. Acoust. Soc. Am. 85 (1989) 1676-1680.

(5) Frisina R.D., Smith R.L. and Chamberlain S.C., Hear. res. 44 (1990) 99-122.

(6) Arle J.E. and Kim D.O., Biol. Cybern. 64 (1991) 273-283.

(7) Banks M.I. and Sachs M.B., J. Neurophysiol. 65 (1991) 606-629.

(8) Berthommier F., "Neural mapping of sensory inputs in the auditory system", Third Cognitiva Symposium, T.Kohonen \& F.Fogelman-Soulie Eds, Madrid Spain November 1990 (North Holland, 1991) pp. 25-34.

(9) Hewitt M.J., Meddis R. and Shackletou T.M., J. Acoust. Soc. Am. 91 (1992) 2096-2109.

(10) Lorenzi C., Berthommier F. and Tirandaz N., J. Acoust. Soc. Am. 93 N 4, Pt.2 (1993) 2313. 